\title{
Interphase Mass Transfer- An Important Mass Transfer Phenomenon
}

\author{
Dr Sunil Jayant Kulkarni \\ Gharda Institute of Technology, Lavel. Khed. Maharashtra, India
}

*Corresponding Author: Dr Sunil Jayant Kulkarni, Gharda Institute of Technology, Lavel. Khed. Maharashtra. India

\begin{abstract}
Heat and mass transfer are very important in the petroleum, chemical and biotechnology engineering. For example, the phenomenon like wax deposition can be analysed by heat and mass transfer studies. In Proton exchange membrane fuel cells also, interphase mass transfer investigations have become important.Many investigations are based on the volume-of-fluid model. In many applications, studies on air liquid interphase mass transfer are important. Heat and mass transfer in two phase system is affected by the interfacial phenomenon, bubble sizes, viscosity, density, temperature, pressure and many other system specific factors. Many investigators have carried out investigations on interphase mass transfer.
\end{abstract}

Keywords: Concentration, equilibrium, diffusion, convection, coefficient

\section{INTRODUCTION}

Various theories were proposed in past to explain interphase mass transfer. For the case of gas liquid interphase mass transfer, it is well known fact that for every concentration in one phase, there is equilibrium concentration in other phase. The departure from this equilibrium state is causing the mass transfer. Wetted wall column experiments were considered for understanding of two resistance concepts [1,2]. Theories namely Film theory, penetration theory and surface renewal theory were proposed by various investigator to explain the interphase mass transfer and relation between diffusivity and mass transfer coefficient. Interphase mass transfer has been interesting area of investigation because of its complexity and importance in mass transfer in many processes[3,4].

Heat and mass transfer are very important in the petroleum, chemical and biotechnology engineering. For example, the phenomenon like wax deposition can be analysed by heat and mass transfer studies[5]. In Proton exchange membrane fuel cells also, interphase mass transfer investigations have become important[6].Many investigations are based on the volume-of-fluid (VOF) model[6-8]. In many applications, studies on air liquid interphase mass transfer are important $[9,10]$. Heat and mass transfer in two phase system is affected by the interfacial phenomenon, bubble sizes, viscosity, density, temperature, pressure and many other system specific factors[11-15]. Many investigators have carried out investigations on interphase mass transfer. This review summarizes some recent and important investigations on this topic.

\section{LITERATURE ON INTERPHASE MASS TRANSFER}

In industrial processes, mass transfer takes place simultaneously by diffusion and convection [16]. For accurately defining a process design, accurate representation of the mass transfer area and mass transfer coefficient is very important[16,17]. Packed beds are used generally with different types of internals for absorbing gases. Monoethanolamine(MEA) is used for investigations on carbon dioxide absorption in the mass transfer studies. As the reaction between MEA and Carbon dioxide $\left(\mathrm{CO}_{2}\right)$ is fast both gas and liquid side mass transfer coefficient are significant but cannot be determined due ti rapid reaction. Volumetric mass transfer coefficient is relatively constant throughout the experiments(17). To compare the experimental results, Proceed Process Simulator (PPS) was used by Pinto et al.[17]. The results were in perfect agreement with each other. The film theory was used to calculate enhancement factor. Billet and Schultes correlation corelations were used by them to estimate The interfacial area and the liquid side mass transfer coefficient[18]. They calculated gas side 
coefficient from Onda and coworkers correlation[19]. According to these studies volumetric mass transfer coefficient was $0.2 \mathrm{~m} / \mathrm{s}$ for all runs. They observed that there is a strong interaction between the liquid side mass transfer coefficient, gas side mass transfer coefficient and interfacial mass transfer area. This is the reason for appearance of constant volumetric mass transfer coefficient.

Single drop experiments for estimation of mass transfer coefficient is very promising method[20]. In this, behaviour of a single drop determines the performance of extraction column. Huang et al. used chloroform-ethanol-water system for the mass transfer system. In this system, Chloroform forms the continuous phase while deionized water, the dispersed phase. Ethanol is the solute. Wilke-Chang equation is used for calculation of the diffusion coefficients. They observed that The overall mass transfer coefficient increased with the drop size and temperature. Also, it decreased with the initial solute concentration. For larger diameter or higher solute concentration, higher level of instability was observed.

Morsi and Basha studied various concepts, theories and models for gas-liquid, gas-solid and gas liquid-solid systems[21].They also discussed various aspects of Slurry Bubble Column Reactors. According to them, mass transfer in multiphase system is critical for the development of numerous industrial processes.

An investigation on mass transfer in isolated bubbles was carried out by Roudet et al.[22]. They analysed interface mass fluxed of pure oxygen rising in the bubble. They identified two main regions of interfacial oxygen transfer and transport. They observed that in the thin film between the bubble and wall the oxygen is transported by molecular diffusion. External flow sweeps the bubble, and the oxygen is transferred in the wake. According to them, convection modifies the mass boundary layer and enhances the mass transfer.Their analysis indicated that the liquid films are far from being saturated in oxygen. It was also observed that, the mass fluxes measured either for the total mass transfer or for the transfer in the films are not so different.

The effects of surfactant monolayers on natural convection heat transfer and evaporative mass transfer were studied by Bower[23]. They observed that the surfactants changes hydrodynamic boundary condition at the interface from shear-free for the case of the clean surface to one that supports shear. According to them convective motion of water is dampened by the presence of surfactants.

Pappas investigated the interfacial mass transfer of acids (by-products) from the organic to the aqueous phase in the halobutyl rubber production process[24]. In this investigation, they studies the effect of parameters, such as organic phase viscosity and presence of calcium stearate solids. the size and stability of the emulsion in the presence calcium stearate. They used butyl rubber for modifying the viscosity of the solution. There was sharp decrease in mass transfer coefficient with increase in the organic phase viscosity. They observed that calcium stearate addition enhanced the mas transfer coefficient till $5 \mathrm{~g} / \mathrm{l}$. Further addition affects adversely the mass transfer coefficient due to stearic acid formation which hinders the contact.

Zhang et al. carried out investigation on the hydrodynamics variation and mass transfer characteristics of Taylor flow along long serpentine microchannels[25]. Taylor flow is gas-liquid flow pattern that consists of elongated bubbles with equivalent diameter usually having diameter many folds that of the channel diameter which is separated by liquid slugs[26]. They investigated the gas-liquid mass transfer process of $\mathrm{CO}_{2}$ in water. Also they studied length, velocity and the mass transfer performance. Findings in this investigation provided important information to understand the dynamic change of gas-liquid Taylor flow mass transfer in microchannels.

Baniamerian et al. studied annular flow regime for entrainment mass transfer[27]. They used carbon dioxide as a refrigerant. In annular flow, high pressure vapour phase produce waves on liquid surface. These waves play important role in entrainment mass transfer. According to them, undercutting of the waves causes liquid droplets transfer into vapor core. They observed that entrainment decreases with increasing the fluid surface tension. Also there is a decrement in number of interfacial waves with wavelength. According to these studies, decrease in the number of waves prevails the increase in wave's amplitude. This investigation underlined that the least mass transfer ratio among the widelyused refrigerants. 
Colombet et al. investigated rising bubbles in homogeneous swarm for studying the dynamics and mass transfer phenomenon[28]. They observed that presence of surfactants causes slight increase of the liquid film thickness around the bubble.

Sherwood number was identical with single bubble rising at same Reynold's number. AmmoniaWater Desorption in Microchannel Geometries was investigated by Determan[29]. Their study indicated that the compact geometry was suitable for all components in an absorption heat pump.

A semiempirical two-zone model was proposed for the gas liquid interfacial area by Larachi et al.[30]. It was possible to determine volumetric mass transfer coefficient by using this model. Liquid and gas non idealities were considered while applying rigorous thermodynamic model. In this investigation, effect of pressure, gas and liquid superficial velocities, liquid viscosity, and packing size on the gasliquid interfacial mass transfer on interfacial mass transfer was examined. They concluded that an increase in pressure at the expense of increased pressure drops and gas holdups. Also they found that the interfacial areas increase in trickle flow regime with increase in viscosity and spherical and nonporous particles had the lowest interfacial areas. They identified two zone flow patterns with a liquid-free gas continuous phase and a gas-liquid film emulsion flowing down the packing.

In many mass transfer applications, drops and bubbles are dispersed in another immiscible phase[31]. Major parameters in mass transfer operations are the interfacial area between the two phases and the transport properties of solute components in the bulk and at the interface. The phenomenon of formation of droplets has numerous applications in petrochemical and metallurgical processes, pharmaceutical productions, food processing technologies, particle production, microencapsulation and generation of emulsions. Generally formation, free-fall, and coalescence are three stages in the lifetime of a drop[31].

Low solubility of $\mathrm{CO}$ and $\mathrm{H}_{2}$ in the liquid mediumis the limiting factor for the syngas (mixture of $\mathrm{CO}$, $\mathrm{H} 2$ and $\mathrm{CO} 2$ ) fermentation[32]. Liu et al. measured the overall volumetric mass transfer coefficient for oxygen in sparged and non-sparged vessel[32]. They observed that by increasing the air flow rates and agitation speeds, the mass transfer coefficient of oxygen increased. At high pressure lower volumetric gas rate causes the decrease in mass transfer coefficient.

Haghnegahdar et al. carried out an investigation on effect of surfactants on bubble shape and size in a milli channel[33]. They used high-resolution microfocus X-ray imaging for this investigation. They observed that presence of surfactants causes slight increase of the liquid film thickness around the bubble.

Nosratinia et al. carried out investigation on mass transfer coefficients under jetting conditions [34].They chose n-Butanol-succinic acid-water with low interfacial tension for these liquid liquid extraction experiments. They investigated factors affecting mass transfer coefficients such as jet velocity, nozzle diameter and the height of the continuous phase above the nozzle.With increase in nozzle diameter, the mass transfer coefficient increased. This investigation highlighted the importance of mass transfer during $\mathrm{g}$ the jet formation and breakage.

Kharangate et al. investigated vertical up flow condensation in a circular tube[35]. They explored condensation of FC-72 fluid for mass transfer studies. They used An axisymmetric 2-D computational model for void fraction and heat transfer coefficient.

Maesa and Soulaine explored volume of fluid method for simulation of species transfer across interface[36]. Volume of fluid method can be geometric or algebraic. Geometric method can achieve better precision with accurate interface reconstruction as this do not create numerical diffusion. For complicated geometries, algebraic method is suitable.

Martin and Hudson carried out investigation on two phase flow[37]. They investigated Mass transfer and interfacial properties in microchannel flow. According to them, molecular mass transfer and drop circulation affect the performance of microfluidic devices. Emulsion behaviour is also affected by interfacial properties. In their investigation, they used mineral oil as continuous phase. They observed that surfactant adsorption affects the Interfacial flow. A mixed kinetic-diffusion limited model described the surfactant mass transfer[21]. 
Singler droplet experiments are used for studying mass transfer for liquid liquid extraction[38]. Droplet formation, rise and coalescence ate three steps in the droplet experiments. Their results indicated that major part of the resistance is located at the interface between the phases. They used two film theory for this purpose.

Interfacial mass transfer rates are affected by the presence of surface contamination[39]. Their research indicated that the mass transfer thickness thickens because of presence of the contamination.

\section{CONCLuSion}

Interfacial mass transfer rates are affected by the presence of surface contamination. Their research indicated that the mass transfer thickness thickens because of presence of the contamination. Singler droplet experiments are used for studying mass transfer for liquid liquid extraction. Droplet formation, rise and coalescence ate three steps in the droplet experiments. Molecular mass transfer and drop circulation affect the performance of microfluidic devices. Emulsion behaviour is also affected by interfacial properties. Presence of surfactants causes slight increase of the liquid film thickness around the bubble. presence of surfactants causes slight increase of the liquid film thickness around the bubble. The mass transfer in multiphase system is critical for the development of numerous industrial processes.

\section{REFERENCES}

[1] Treybal R E, “ Interphase mass Transfer”, Mass Transfer Operations.McGraw Hill Publishing.Third edition., 104-123, 1981.

[2] Dutta B K, "Interphase Mass Transfer", Principles and Mass Transfer and Seperation Operations, Eastern Economy Edition, pHI learning., pp.122-156., 2007.

[3] NigarKantarcia, FahirBorakb, Kutlu O. Ulgen, Bubble column reactors, Process Biochemistry 40 (2005) 2263-2283. doi:10.1016/j.procbio.2004.10.004

[4] Scha"fer R, Marten C, Eigenberger G. Bubble size distributions in a bubble column reactor under industrial conditions. Exp Therm Fluid Sci 2002;26:595-604.

[5] Zhenyu Huang, Application Of The Fundamentals Of Heat And Mass Transfer To The Investigation Of Wax Deposition In Subsea Pipelines, A dissertation submitted in partial fulfillment of the requirements for the degree of Doctor of Philosophy (Chemical Engineering) in the University of Michigan 2011.

[6] Koz, Mustafa, "Numerical Investigation of Interfacial Mass Transport Resistance and Two-phase Flow in PEM Fuel Cell Air Channels" (2015). Thesis. Rochester Institute of Technology

[7] Li X, Wang W, Zhang P, Li J, Chen G. 2019 Interactions between gas - liquid mass transfer and bubble behaviours. R. Soc. open sci. 6: 190136. http://dx.doi.org/10.1098/rsos.190136

[8] Tse KL, Martin T, McFarlane CM, Nienow AW. 2003 Small bubble formation via a coalescence dependent break-up mechanism. Chem. Eng. Sci. 58, 275-286. (doi:10.1016/S0009- 2509(02)00528-6)

[9] H. M. Faisal Anwar, Estimation Of Mass Transfer Coefficients Using Air-Liquid Interfacial Area In Porous Media, Journal of Environmental Research And Development Vol. 3 No. 2, October-December 2008., 331-341.

[10] Kim H., Rao, P.S.C. and Annable M. D., Determination of effective air-water interfacial area in partially saturated porous media using surfactant adsorption, Water Resour. Res., 33, 2705-2711, (1997).

[11] Woitalka, A., S. Kuhn, and K.F. Jensen. "Scalability of mass transfer in liquid-liquid flow." Chemical Engineering Science 116 (6 September 2014), p.1-8.

[12] V.K. Badam a,*, V. Kumar a , F. Durst a , K. Danov, Experimental and theoretical investigations on interfacial temperature jumps during evaporation, Experimental Thermal and Fluid Science 32 (2007) 276-292. doi:10.1016/j.expthermflusci.2007.04.006

[13] Mohammad Khalilitehrani, An Investigation on Modeling and Simulation of Chilled Ammonia Process using VOF method, Department of Chemical and Biological Engineering Division of Chemical Reaction Engineering CHALMERS UNIVERSITY OF TECHNOLOGY Göteborg, Sweden, 2011

[14] Balkrishna Mehta, Sameer Khandekar*, Investigation of the Heat Transfer Coefficient of Liquid and Gas Bubble Train Flow in a Square Mini-channel Using Infra-Red thermography, 11th International Conference on Quantitative InfraRed Thermography, 11-14 June 2012, Naples Italy

[15] Norman Kirk Yeh, Liquid Phase Mass Transfer in Spray Contactors, Dissertation Presented to the Faculty of the Graduate School of The University of Texas at Austin in Partial Fulfillment of the Requirements for the Degree of Doctor of Philosophy The University of Texas at Austin May 2002. 
[16] A. Burghardt, Interphase Mass Transfer, Chemical Engineering And Chemical Process Technology - Vol. I, Encyclopedia of Life Support Systems (EOLSS).

[17] .Diego D. D. Pintoa , Rob Emondsa , Geert F. Versteeg, Experimental determination of mass-transfer coefficients and area of dumped packing using alkanolamine solvents, The 8th Trondheim Conference on Capture, Transport and Storage. Energy Procedia 86 ( 2016 ) 219 - 228.

[18] R. Billet and M. Schultes, "Prediction of Mass Transfer Columns with Dumped and Arranged Packings: Updated Summary of the Calculation Method of Billet and Schultes," Chemical Engineering Research and Design, vol. 77, pp. 498 - 504, 1999.

[19] K. Onda, H. Takeuchi and Y. Okumoto, "Mass transfer coefficients between gas and liquid phases in packed columns," Journal of Chemical Engineering of Japan, vol. 1, pp. 56 - 62, 1968.

[20] Zhixian Huang, Changshen Ye, Ling Li, Xiaowu Zhang and Ting Qiu*,Measurement And Correlation Of The Mass Transfer Coefficient For A Liquid-Liquid System With High Density Difference, Brazilian Journal of Chemical Engineering, Vol. 33, No. 04, pp. 897 - 906, October - December, 2016 dx.doi.org/10.1590/0104-6632.20160334s20150488.

[21] Badie I. Morsi and Omar M. Basha, Mass Transfer in Multiphase Systems, Mass Transfer - Advancement in Process Modelling Edited by Marek Solecki.,2015, 189-2016. http://dx.doi.org/10.5772/60516

[22] Roudet, Matthieu and Billet, Anne-Marie and Cazin, Sébastien and Risso, Frédéric and Roig, Véronique Experimental Investigation of Interfacial Mass Transfer Mechanisms for a Confined High-ReynoldsNumber Bubble Rising in a Thin Gap. (2017) AIChE Journal, vol. 63 ( $\mathrm{n}^{\circ}$ 6). pp. 2394-2408. ISSN 00011541 : http://dx.doi.org/10.1002/aic.15562

[23] Steven Bower, An investigation of the effects of surfactant monolayers on natural convection heat transfer and evaporative mass transfer, All Dissertations. 795. https://tigerprints.clemson.edu /all_dissertations/795

[24] Pappas, Andreas. 2021. "Solids-stabilized Emulsions with Interfacial Mass Transfer and Aggregate Formation". Loughborough University. https://doi.org/10.26174/thesis.lboro.13337906.v1.

[25] P. Zhang, C. Yao, H. Ma, N. Jin, X. Zhang, H. Lü, Y. Zhao, Dynamic changes in gasliquid mass transfer during Taylor flow in long serpentine square microchannels, Chemical Engineering Science (2018), doi: https://doi.org/10.1016/j.ces.2018.02.018

[26] Panagiota Angeli,Asterios Gavriilidis, Taylor Flow in Microchannels, Encyclopaedia of Microfluidics and Nanofluidics, 2008 Edition | Editors: Dongqing Li .p.77. DOI: https://doi.org/10.1007/978-0-387-489988_1526

[27] Zahra Baniamerian1 *, Ramin Mehdippour1 and Cyrus Aghanajafi, Zahra Baniamerian1 *, Ramin Mehdippour1 and Cyrus Aghanajafi2, Scientific Research and Essays Vol. 7(49), pp. 4186-4195, 17 December, 2012 Available online at http://www.academicjournals.org/SRE DOI: 10.5897/SRE11.878

[28] Damien Colombet, Dominique Legendre, Frédéric Risso, Arnaud Cockx, Pascal Guiraud, Pascal Dynamics and mass transfer of rising bubbles in a homogenous swarm at large gas volume fraction. (2014) Journal of Fluid Mechanics, vol. 763. pp. 254-285. ISSN 0022-1120. http://dx.doi.org/10.1017/ jfm.2014.672

[29] Matthew D. Determan, Experimental and Analytical Investigation of Ammonia-Water Desorption in Microchannel Geometries, Georgia Institute of Technology August,2005

[30] F. Larachi, M. Cassanello, A. Laurent, Gas-Liquid Interfacial Mass Transfer in Trickle-Bed Reactors at Elevated Pressures, Ind. Eng. Chem. Res. 1998, 37, 718-733

[31] Javadi, Aliyar\&Bastani, D \&Taeibi-Rahni, Moha\&Karbaschi, Mohsen \& Miller, Reinhard. (2011). Interfacial Mass Transfer of Growing Drops in Liquid-Liquid Systems.

[32] Liu, K.; Phillips, J.R.; Sun, X.; Mohammad, S.; Huhnke, R.L.; Atiyeh, H.K. Investigation and Modeling of Gas-Liquid Mass Transfer in a Sparged and Non-Sparged Continuous Stirred Tank Reactor with Potential Application in Syngas Fermentation. Fermentation 2019, 5, 75. https://doi.org/10.3390/fermentation 5030075

[33] Mohammadreza Haghnegahdar, Stephan Boden, Uwe Hampel,Investigation of surfactant effect on the bubble shape and mass transfer in a milli-channel using high-resolution microfocus X-ray imaging,International Journal of Multiphase Flow,Volume 87,2016,Pages 184-196,ISSN 03019322,https://doi.org/10.1016/j.ijmultiphaseflow.2016.09.010.

[34] Nosratinia, Ferial, Omidkhah, Mohammad Reza, Bastani, Dariush; Saifkordi, Ali Akbar, Investigation of Mass Transfer Coefficient under Jetting Conditions in a Liquid-Liquid Extraction System, Iran. J. Chem. Chem. Eng, Vol. 29, No. 1, 2010, 1-12. 
[35] Chirag R. Kharangate, Hyoungsoon Lee, Ilchung Park, IssamMudawar, Experimental and computational investigation of vertical upflow condensation in a circular tube, International Journal of Heat and Mass Transfer, International Journal of Heat and Mass Transfer 95 (2016) 249-263. http://dx.doi.org/10.1016 /j.ijheatmasstransfer.2015.11.010

[36] Maes, J \&Soulaine, C 2018, 'A new compressive scheme to simulate species transfer across fluid interfaces using the Volume-Of-Fluid method', Chemical Engineering Science, vol. 190, pp. 405-418. https://doi.org/10.1016/j.ces.2018.06.026

[37] Jeffrey D Martin and Steven D Hudson, Mass transfer and interfacial properties in two-phase microchannel flows , 2009 New J. Phys. 11 115005. doi:10.1088/1367-2630/11/11/115005

[38] Lahdenperä E, Tamminen J, Koiranen T, Kuronen T, Eerola T, et al. (2018) Modeling Mass Transfer During Single Organic Droplet Formation and Rise. J Chem Eng Process Technol 9: 378. doi: 10.4172/2157-7048.1000378

[39] J Wissink, H Herlina, Y Akar, M Uhlmann, Effect of surface contamination on interfacial mass transfer rate, J. Fluid Mech, Cambridge Vol. 830, (Nov 10, 2017): 5-34. DOI:10.1017/jfm.2017.566

Citation: Dr Sunil Jayant Kulkarni." Interphase Mass Transfer- An Important Mass Transfer Phenomenon", International Journal of Clinical Chemistry and Laboratory Medicine (IJCCLM), vol. 8, no.1, pp. 24-29, 2021. http://dx.doi.org/10.20431/2455-7153.0801003

Copyright: (C) 2021 Authors. This is an open-access article distributed under the terms of the Creative Commons Attribution License, which permits unrestricted use, distribution, and reproduction in any medium, provided the original author and source are credited. 